\title{
Brote de Parotiditis Vírica en el Liceo Militar de Acosta Ñu de junio a octubre del año 2016
}

\author{
Outbreak of Viral Parotitis at the Acosta Nu Military \\ Academy from june to october 2016
}

\author{
Laura López ${ }^{1}$, Gladys Arguello ${ }^{1}$, María José Sánchez ${ }^{1}$, Roger Rolón ${ }^{1}$
}

\section{RESUMEN}

Introducción: El presente estudio trata de un brote de parotiditis en un Liceo Militar que se inicia en junio del año 2016 y se prolonga hasta fines de octubre del mismo año. El objetivo fue describir las características epidemiológicas del brote. Métodos: Es observacional, retroprospectivo, de corte transverso de fichas clínicas de cadetes que constan en el archivo del Liceo Militar de Acosta Ñu que abarca el periodo junio a octubre del año 2016 y posterior entrevista a los afectados. Resultados: De 181 cadetes, todos masculinos, con edad media de 16 años, del Liceo Militar de Acosta Ñu. Se tomó como muestra a 115 cadetes (63\%) presentaron parotiditis, sin afectación de las otras glándulas salivales. En 50 casos (44\%) de forma bilateral y 64 casos $(56 \%)$ unilateral. 23 cadetes $(20 \%)$ presentaron complicaciones, como orquitis 22 (19\%) todos unilaterales, pancreatitis 1. En ningún caso se presentó meningitis, encefalitis, miocarditis, todos sobrevivieron. De los cadetes afectados no fueron vacunados (SPR) 103 (90\%), 8 (7\%) recibieron una dosis y $2(2.3 \%)$ dos dosis. Los casos ocurridos $(63 \%)$ fue debida a la falta de vacunación completa (Triple Viral, 2 dosis) y a las condiciones de hacinamiento de los cadetes. Conclusión: El brote de parotiditis ocurrido en el Liceo Militar de Acosta Nu, se caracterizó por la alta incidencia de contagios debido a la baja o nula cobertura vacunal y a las condiciones de hacinamiento de los cadetes. Por lo tanto recomendamos que al ingreso a toda institución que incluya residencia temporal o fija en condiciones de hacinamiento, la exigencia mínima debiera ser la presentación de un carnet de vacunación completo.

Palabras claves: Brote, parotiditis, complicaciones, carnet de vacunación.

\section{ABSTRACT}

Introduction: This study describes an outbreak of mumps in a Military Academy that began in June 2016 and lasted until the end of October of the same year. Objective: To describe the epidemiological characteristics of the outbreak. Materials and Methods: This was an observational, retroprospective, cross-sectional review of the medical records of cadets at the Acosta Nu Military Academy who presented for medical evaluation from June to October, 2016 and with subsequent interviews with identified patients with parotitis. Results: Of 181 cadets, all were male, with an average age of 16 years. We selected a sample of 115 cadets $(63 \%)$ who presented parotiditis, without involvement of other salivary glands. In 50 cases $(44 \%)$ the illness was bilateral and in 64 cases $(56 \%)$, the illness was unilateral. 23 cadets $(20 \%)$ presented complications, such as orchitis 22 (19\%) all unilateral, and one patient had pancreatitis. No patient had meningitis, encephalitis, or myocarditis, and there were no deaths. Of the affected $103(90 \%)$ cadets were not vaccinated with the measles-mumps-rubella (MMR) vaccine, $8(7 \%)$ had received one dose and $2(2.3 \%)$ received two doses. The cases that occurred $(63 \%)$ were due to the lack of complete vaccination (MMR vaccine, 2 doses) and to the overcrowded conditions of the cadets. Conclusion: The Outbreak of parotitis, which occurred at Acosta Nu Military Academy, was characterized by a high incidence of infections due to incomplete or no vaccination coverage and the overcrowded conditions of the cadets. Therefore, we recommend that upon admission to any institution that includes temporary or fixed residence in overcrowded conditions, the minimum requirement should be the presentation of a completed vaccination card.

Keywords: Outbreak, parotitis, complications, vaccination card

\footnotetext{
${ }^{1}$ Hospital Central de las Fuerzas Armadas de la Nación (FF.AA). Asunción, Paraguay.

Correspondencia: Laura López Correo:lyla_u89@hotmail.com

Conflicto de Interés: Los autores declararan que no poseer conflicto de interés

Recibido: 24/11/2017. Aceptado: 25/04/2018

DOI: https://doi.org/10.31698/ped.45012018005
} 


\section{INTRODUCCIÓN}

La parotiditis es una infección viral aguda, que suele tener una evolución benigna cuyo agente es un Paramyxovirus del mismo grupo que los virus de la parainfluenza ${ }^{(1)}$. En la era de la prevacuna, la tasa de ataque más alta era entre los niños en la escuela primaria, y la mayoría de los adolescentes mostraron evidencia de infección previa ${ }^{(2)}$.

El único reservorio conocido es el hombre, no se conoce el estado de portador. El mecanismo de transmisión es por vía aérea, por secreciones rinofaringeas, fómites y por contacto directo con la saliva de una persona infectada. Aunque la parotiditis durante el embarazo se ha relacionado casualmente con abortos y con fibroelastosis endocárdica, su teratogenicidad no ha sido comprobada totalmente ${ }^{(2,3)}$.

Las paperas son difíciles de diferenciar clínicamente de otras afecciones que causan hinchazón de las principales glándulas salivales. Varios agentes virales pueden inducir síntomas que imitan los de las paperas, y la hinchazón de las glándulas parótidas puede ser causada por diversas infecciones bacterianas ${ }^{(5,6)}$. Si la parotiditis es causada por bacterias, generalmente producen otros síntomas, como la colección purulenta dentro o alrededor de la glándula parótida ${ }^{(5)}$. Este trabajo de basa específicamente sobre la parotiditis viral endémica. El período de incubación oscila entre 14 a 21 días, con un promedio entre 14-25 días. El virus ha sido aislado de la saliva desde 7 días antes hasta 9 días después del inicio de la parotiditis ${ }^{(1,2)}$. Es obligatoria la notificación de la misma y para su prevención es necesario educar a las madres acerca de la enfermedad y las medidas que pueden ser aplicadas para evitar el contagio ${ }^{(7)}$. A continuación se exponen los principales síntomas con mención de las complicaciones.

La forma parotídea es la más frecuente. El período prodrómico es breve, de uno a tres días de duración, y se manifiesta con síntomas poco específicos: anorexia, cefaleas, fiebre y malestar general. En el período de estado el dato clínico fundamental es la inflamación de la glándula parótida uni o bilateral. La inflamación bilateral ocurre en $75 \%$ de los pacientes ${ }^{(6,8)}$.
También existen alteraciones glandulares extra salivales, que coincide con la parotiditis o aparece pocos días después de esta, y se considera como complicaciones de la enfermedad. Su patogenia más probable es la diseminación tardía del virus, a partir del foco parotídeo y las glándulas afectadas con mayor frecuencia son los testículos, el páncreas y el ovario, dando cuadros de orquitis, pancreatitis y ooforitis $^{(2,6,8)}$.

La orquitis es relativamente frecuente en el niño púber y en los adultos jóvenes (hasta en $35 \%$ ), pero es excepcional antes de los 10 años. Por lo general aparece durante la primera semana de la enfermedad o poco después, pero puede preceder a la tumefacción parotídea e incluso puede presentarse sin afección de las glándulas salivales. En la gran mayoría de los casos es unilateral, y se presenta con fiebre, dolor y tumefacción de uno o los dos testículos, acompañada, en ocasiones, de epididimitis. Cuando la inflamación es muy intensa y bilateral, hay peligro de esterilidad por necrosis, el edema puede comprimir el tejido glandular y producir atrofia, aunque rara vez esta es total y bilateral. La orquitis por el virus de la parotiditis puede constituir un factor de riesgo para el desarrollo posterior de cáncer testicular en un 3,5\% ${ }^{(2,8)}$.

La pancreatitis se manifiesta por brusca elevación febril, dolor abdominal muy intenso localizado en el epigastrio, vómitos, a veces heces grasosas y curva de glicemia de tipo diabetoide; excepcionalmente hay glucosuria. El curso es subagudo, con recaída en los síntomas digestivos (diarrea, indigestiones). La diabetes tipo I es una secuela excepcional: el virus urliano actuaría como desencadenante en niños genéticamente predispuestos y en los que ya tuvieran lesiones de las células beta de los islotes de Langerans. La ooforitis, menos frecuente, aparece en las púberes; su sintomatología principal consiste en dolor localizado en las fosas ilíacas y pasa muchas veces inadvertidas ${ }^{(2,5)}$.

Más raro es el compromiso de otras glándulas, como la mamaria, la tiroides, la paratiroides, el timo, las glándulas de Bartolini, las glándulas lagrimales y el saco lagrimal. La inflamación de todas ellas es benigna y revierte sin consecuencias ${ }^{(8)}$. 
Afección nerviosa, ante todo hay que destacar la meningitis. Hay una forma oculta asintomática, presente en $50 \%$ de todas las parotiditis, que sólo es detectable por examen del líquido cefalorraquídeo. La meningitis parotídea manifiesta es menos frecuente y suele coincidir con la inflamación de las glándulas parotídeas; más rara vez aparece antes o después de la inflamación de las mismas ${ }^{(2,8)}$.

El cuadro clínico presenta fiebre alta o estado subfebril, vómito, cefaleas, rigidez de nuca y otros signos meníngeos positivos; en el líquido cefalorraquídeo hay características típicas de las meningitis virales: es claro o ligeramente opalescente, con albúmina y glucosa poco modificadas y marcada pleocitosis que llega a 500 o más células de predominio linfocitario ${ }^{(8)}$.

El curso de estas meningitis urlianas dura de 2 a 3 semanas y su pronóstico es benigno. Existen formas de meningoencefalitis mucho menos frecuentes, que cursan con somnolencia, sopor y convulsiones; son responsables de los raros casos de muerte por parotiditis y pueden dejar secuelas de tipo neurológico y psíquico por lesiones irreparables del sistema nervioso. Las mielitis aisladas son raras. También es posible la aparición de un síndrome de Guillain-Barré y el compromiso de los nervios craneales motiva raramente neuritis del nervio óptico o del facial; al respecto, es más frecuente la afección del nervio acústico, que deja como secuela una sordera permanente de percepción, habitualmente unilateral, hasta en $4 \%$ de los pacientes; las laberintitis son más raras ${ }^{(2,5,8)}$.

Otras alteraciones, algunos datos epidemiológicos y serológicos han señalado la posibilidad de que el virus de la parotiditis motive malformaciones congénitas, pero no es un hecho plenamente demostrado, lo mismo que la supuesta relación con la fibroelastosis endocárdica congénita. La miocarditis no es excepcional, pero suele ser leve o manifestada únicamente por alteraciones del electrocardiograma (depresión del espacio ST) y predomina en la edad adulta( ${ }^{(8)}$.

La hepatitis ha sido descrita con poca frecuencia y gravedad, al igual que las artritis, las cuales son, por lo general, migratorias. La nefritis es una posible complicación. También hay casos de púrpura trombocitopénica, como en otras afecciones virales. En el globo ocular, además de la dacryoadenitis, excepcionalmente aparecen: neuritis óptica, escleritis, uveítis, queratitis y trombosis venosa central ${ }^{(4,5,6,8)}$.

El padecimiento de parotiditis por la gestante al final del embarazo puede producir parotiditis neonatal ${ }^{(3)}$. En raras ocasiones aparece un exantema urticariado o máculo-papuloso discreto, de predominio en el tronco.

El tratamiento es puramente sintomático y la mejor prevención consiste en la vacunación, por lo general asociada a la del sarampión y la rubéola ${ }^{(5,8)}$.

La Enfermedad Urliana presenta una estacionalidad clara con un pico principalmente en inviernoprimavera, pero es endémica durante todo el año. La situación actual en Paraguay, haciendo referencia al Boletín Epidemiológico del MS y BS (Figura 1), ha demostrado que en los últimos tres años los casos han aumentado de 177 casos (3 por cada 100.000 habitantes) a 1007 casos (14 por cada 100.000 habitantes), estos últimos notificados en el año $2017^{(5)}$.

Cabe destacar que el Programa Ampliado de Inmunización informa que la cobertura vacunal de la SPR (Triple viral) ha llegado a un $87 \%$, dentro del área Central, siendo una cobertura vacunal ideal el 95\%de la población (OMS). Con un porcentaje de $87 \%$ en la primera dosis, pero no así con la segunda dosis, alcanzado $78 \%$ en el mejor de los casos ${ }^{(4,5)}$.

Teniendo en cuenta que la efectividad de la vacuna alcanza hasta un $95 \%$ con la segunda dosis, se plantea que la causa de esta enfermedad endémica se podría deber a la disminución en las dosis de refuerzo $\left(2^{\circ}\right.$ dosis) que presenta la población. Sin embargo hace varios años que no recibimos notificaciones de enfermedades como el sarampión y la rubeola, contenidas en la misma vacuna ${ }^{(5)}$.

La vacuna anti parotiditis contiene virus vivos atenuados y fue introducida al Paraguay en el año 2002 mediante Triple Viral o SPR ${ }^{(8)}$. La primera dosis de la vacuna debe administrarse a modo de rutina a los niños entre 12 y 15 meses de edad, con una segunda dosis o refuerzo de la vacuna entre niños de 4 y 6 años de edad ${ }^{(4,5)}$. La segunda dosis o refuerzo 
puede administrarse antes de los 4 años de edad, siempre que haya trascurrido al menos 28 días desde la primera dosis, y el intervalo con la dosis de la vacuna contra la varicela sea de al menos 90 días ${ }^{(5)}$.

Un estudio realizado en Estados Unidos arrojó datos sobre la eficacia del 80\% (rango de 62 a 91\%) de 1 dosis de vacuna. Y la efectividad de 2 dosis ha sido algo más alta (rango 79 a 95\%) ${ }^{(8)}$. Otros estudios, realizados en el mismo país a fines del año 2006, indican que la inmunidad inducida por la vacuna puede disminuir, lo que posiblemente explique la ocurrencia de parotiditis en el grupo etario de entre 15 y 24 años ${ }^{(6,9)}$.

En Paraguay no se ha realizado hasta la actualidad estudios sobre la efectividad entre 1 o las 2 dosis de la vacuna ${ }^{(5)}$.

EL objetivo del siguiente estudio fue caracterizar el brote de Parotiditis ocurrido en el Liceo Militar
Acosta Nu en la ciudad de Ypané del Departamento Central, iniciado el 29 de junio del año 2016, notificado a la Red de Vigilancia Epidemiológica del Hospital Militar Central de Las Fuerzas Armadas. Donde fueron afectados 115 cadetes, quedando como consecuencia una institución con actividades académicas paralizadas, por un tiempo de 2 semanas a causa del ausentismo de sus alumnos residentes (63\%) en dicho lugar. Sin mencionar el valor económico que afectó a la institución en la creación de cohortes y provisión de alojamiento con las comodidades necesarias para el reposo de cadetes y favorecer el aislamiento de los afectados como medida de control de la propagación del virus al resto de la población.

La aparición de enfermedades prevenibles mediante la vacunación representa una oportunidad para remarcar la importancia en la vigilancia y exigencia del carnet de vacunación completo ${ }^{(5,7,8)}$.

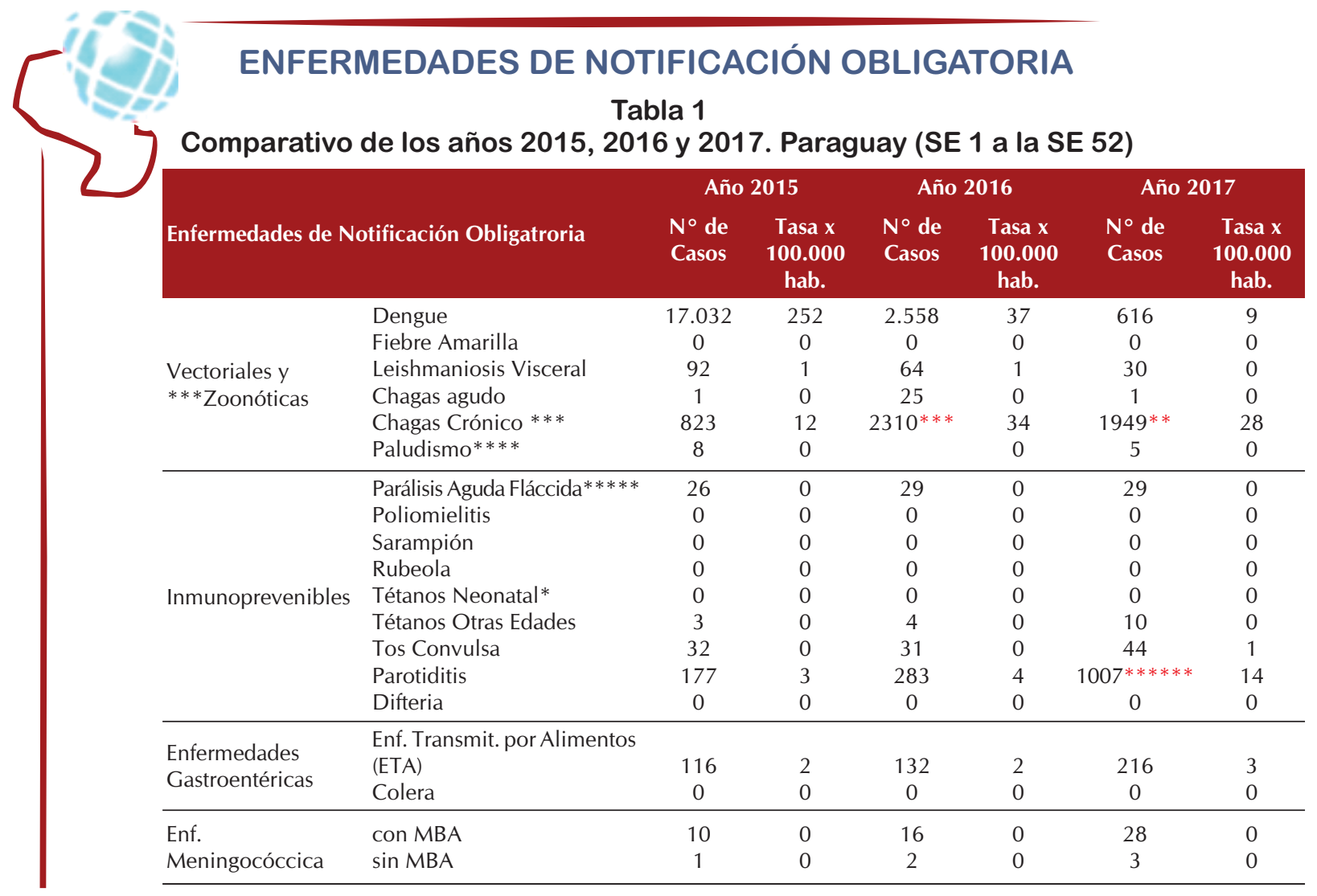

Figura 1. Boletín epidemiológico MS y BS del 2017 (Incidencia de enfermedad de notificación obligatoria en los años 2015, 2016, 2017. ${ }^{(4)}$ 


\section{METODOLOGÍA}

Estudio observacional, retro prospectivo, de corte transverso, se realizó una revisión de fichas clínicas de cadetes que constan en el archivo del Liceo Militar de Acosta Nu y abarca el periodo junio a octubre del año 2016.

La investigación se realizó en un Instituto de Enseñanza Media con Formación Militar (Liceo Militar de Acosta Nu) ubicado en la ciudad de Ypané del Departamento Central situado a $27 \mathrm{~km}$ de la ciudad de Asunción.

La población de referencia fue de 181 cadetes del Liceo Militar. Se tomó como muestra 115 cadetes que presentaron parotidis, en el tiempo de cuatro meses, de sexo masculino, con edades comprendidas entre 16 a 20 años, con una media de 16 años del primero, segundo y tercer curso de la media, y aquellos casos en cadetes que tuvieron origen en la cadena de transmisión en el instituto (Por ejemplo: personal de enfermería del servicio).

Definición de caso: persona que presentó inflamación unilateral o bilateral, sensible al tacto y autolimitada de la parótida u otras glándulas salivares (submaxilar y/o sublingual) superior a 2 días y sin otras causas aparentes ${ }^{(5)}$, pertenecientes al Liceo Militar de Acosta Ñu durante el periodo junio a octubre del 2016.

Definición de caso confirmado: basado en la clínica y predominancia de linfocitos en el Hemograma y Proteína $C$ reactiva negativa. No fueron realizados estudios confirmatorios de serología Ig M ni PCR (Reacción de Polimerasa en cadena) por falta de disponibilidad en el servicio.

Definición de brote: aparición de 2 o más casos clínicos de parotiditis, cuyas fechas de inicio de síntomas difieren menos de un periodo de incubación (de 14 a 25 días) ${ }^{(5,8)}$.

Periodo de brote: desde 2 días antes de la fecha de inicio de los síntomas del primer caso, hasta 5 días después de la fecha de inicio de los síntomas del último caso $^{(8)}$ (del 29 de junio al 23 de octubre).
El caso índice se registró el 29 de junio del año 2016 (semana epidemiológica 30) en un cadete de 16 años, procedente de la ciudad de Nemby, que presentó síntomas como fiebre, tumefacción en región parotídea, cefalea y un esquema de vacunación incompleto para la edad. Consulta al centro asistencial de su comunidad donde fue notificado el caso, recibió tratamiento ambulatorio, posteriormente con reposo médico en la casa. No presentó complicaciones.

Al interrogatorio el paciente refiere que compartió viaje en ómnibus con un compañero del Liceo, y que este, compartía a la vez habitación con otros cadetes, se cree que en ese periodo ocurrió la diseminación del virus. El último caso se notificó el día 23 de octubre (semana epidemiológica 42).

Se destaca un detalle del estudio, se menciona el porcentaje de los no afectados por el virus de la parotiditis $(37 \%)$, que mediante un interrogatorio exhaustivo, que consta en la ficha médica, luego de 8 meses al término del brote, para determinar las posibles variables de la no afectación por la parotiditis, y se concluyó que el 15\% recordó haber presentado la enfermedad durante su infancia con libreta de vacunación incompleta, 10\% no recuerda haberla padecido y no se obtuvo datos del carnet de vacunación y solo el $2 \%$ no recuerda haberla padecido pero con libreta de vacunación completa.

Se definió vacunado a aquella persona con datos de vacunación registrados en su carnet o en su historia clínica de atención primaria, y correctamente vacunado cuando aparecían con 2 dosis, la primera a $\operatorname{los} 12$ meses de edad y otro refuerzo a los 4 años ${ }^{(5)}$.

Para la investigación se recogieron los datos de las fichas clínicas de cadetes que constan en el archivo de la institución. Por otra parte, prospectivamente fue realizada una entrevista a los cadetes afectados 8 meses después de la enfermedad como seguimiento evolutivo. Un dato obtenido que llamó la atención fue que uno de los cadetes que había padecido orquitis, presentaba hasta la actualidad molestias en ambos testículos de manera esporádica y refiere disminución de tamaño de uno de ellos.

Se utilizaron medidas de control de brote como formación de cohortes dentro del Liceo Militar, 
donde fueron alojados para reposo médico y le fueron otorgados de cuidados por parte del servicio de enfermería de la institución. Posteriormente al brote, se realizaron reuniones médicas informativas con las autoridades encargadas de la institución brindando información sobre el esquema de vacunación y se solicitó la exigencia del carnet de vacunación a los aspirantes a cadete que ingresarán al Liceo y como también la vacunación a los no afectados dentro de la institución, como medida preventiva de futuros brotes de la enfermedad y otras prevenibles mediante la vacunación.

\section{RESULTADOS}

\begin{tabular}{lcc}
\hline Síntomas & Casos & \% \\
\hline Inflamación de las parótidas & 115 & 100 \\
\hline Inflamación unilateral & 50 & 44 \\
\hline Inflamación bilateral & 64 & 56 \\
Cefalea & 51 & 45 \\
\hline Fiebre & 69 & 60 \\
Orquitis & 22 & 19 \\
\hline Pancreatitis & 1 & 1 \\
\hline Hospitalización & 8 & 7 \\
\hline
\end{tabular}

Figura 2. Descripción del brote.

Durante el periodo de brote, de 181 cadetes, masculinos todos, con una media de edad de 16 años, fueron afectados 115 (63\%).El cuadro clínico se caracterizó por tumefacción parotídeas $(100 \%)$, cefalea y fiebre (Figura 2). De total de afectados 8 (7\%) requirieron hospitalización con una media de duración de internación de 8 días. Los afectados que no fueron internados requirieron reposo en la casa por un promedio de 2 semanas.

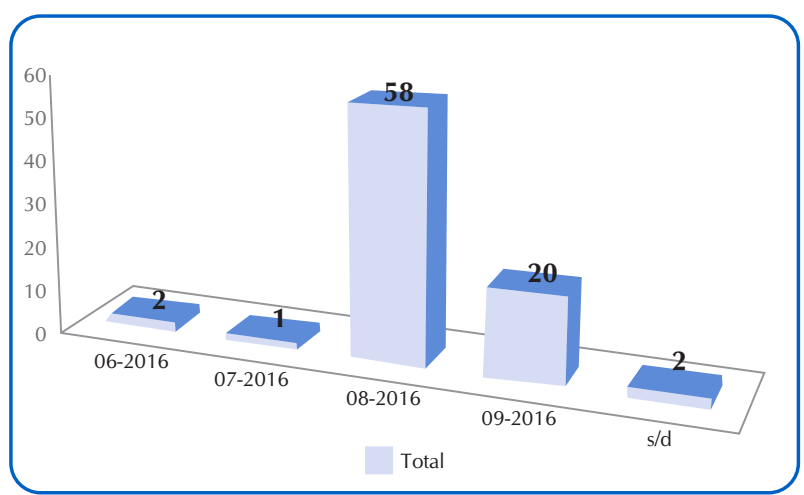

Figura 3. Transmisibilidad.

Llamó la atención que uno de los cadetes que había padecido orquitis, presentaba hasta la actualidad molestias en ambos testículos de manera esporádica y refiere disminución de tamaño de uno de ellos. Las complicaciones observadas (Figura. 2) fueron orquitis $22(19 \%)$, pancreatitis 1. En ningún caso se presentó meningitis, encefalitis ni miocarditis. No se registró caso de mortalidad.

De los cadetes afectados no fueron vacunados (Triple Viral) 103 (90\%), 8 (7\%) recibieron una dosis y2 $(2.3 \%)$ dos dosis.

El 2.3\% que recibió 2 dosis de la SPR, ninguno de ellos presentó complicaciones. Ver Fig.2, Manifestaciones clínicas y complicaciones.

El periodo de mayor transmisibilidad fue en el mes de agosto donde se registró el $58 \%$ de los casos, correspondientes las 30, 31, 32 y 33 semanas epidemiológicas del año 2016 ${ }^{(4)}$. (Figura 3). En agosto se observa el mayor periodo de transmisibilidad (58\%).

El diagnóstico fue realizado predominantemente por las manifestaciones clínicas y el examen clínico, ya que no se contaba con disponibilidad de serologías Ig M ni PCR en tiempo real (Reacción en cadena de la polimerasa en tiempo real $)^{(4)}$.

\section{DISCUSIÓN}

Creemos que la alta incidencia de la enfermedad fue debida a la baja o nula cobertura vacunal (SPR 2 dosis $2.3 \%$ ). Como mencionamos anteriormente, 1 dosis de la vacuna tiene una eficacia del $80 \%$. Y en 79 a $95 \%$ la efectividad de 2 dosis es alta ${ }^{(9)}$. En un estudio realizado acerca de un brote de parotiditis en escolares se señala que la inmunidad inducida por la vacuna puede disminuir, lo que posiblemente explique la ocurrencia de parotiditis en el grupo etario de entre 15 y 24 años ${ }^{(10)}$. Atribuimos al mismo fundamento el brote de la enfermedad ocurrido en los cadetes del Liceo Militar de Acosta Nu, donde el promedio de edad fue de 16 años, incluyendo a los que presentaron vacunación completa (SPR 2 dosis) La situación actual en Paraguay, haciendo referencia al Boletín Epidemiológico del MS y BS, ha demostrado que en los últimos tres años los casos han aumentado de 177 casos (3 por cada 100.000 habitantes) a 1007 casos (14 por cada 100.000 habitantes), estos últimos notificados en el año $2017^{(4)}$. 
Según el Programa Ampliado de Inmunización (PAI) informa que la cobertura vacunal de la SPR (Triple viral) en el año 2017 ha llegado a un 87\% (Central), $87 \%$ en la primera dosis, $78 \%$ con la segunda dosis ${ }^{(5)}$

Un estudio realizado en Estados Unidos arrojó datos sobre la eficacia del $80 \%$ (rango de 62 a 91\%) de 1 dosis de vacuna. Y la efectividad de 2 dosis ha sido algo más alta (rango 79 a 95\%) ${ }^{(10)}$ Otros estudios, realizados en el mismo país a fines del año 2006, indican que la inmunidad inducida por la vacuna puede disminuir, lo que posiblemente explique la ocurrencia de parotiditis en el grupo etario de entre 15 y 24 años ${ }^{(9)}$. En Paraguay no se ha realizado hasta la actualidad estudios sobre la efectividad entre $1 \mathrm{o}$ las 2 dosis de la vacuna.

Si bien, es cierto que no se presentaron complicaciones los síntomas tuvieron una duración igual a la del promedio como en el caso de la literatura consultada ${ }^{(10)}$.

La curva epidémica de los 115 casos, a lo largo de los 5 meses de duración, es la de un brote de tipo prosodémico (transmisión de persona a persona). El cuadro clínico presentó una evolución favorable, con complicaciones no severas, que coincide con la literatura ${ }^{(5,9,10)}$.

Las complicaciones se presentaron en los cadetes

\section{REFERENCIAS}

1. Harry A, Feldman, Mumps. En: Evans AS, Brachman, PS. Editores. Viral Infections Humans: Epidemiology and Control. Plenum Publishing Corporation; 1991.

2. Dayan G, Quinlisk M, Parker A, et al. Recent Resurgence of Mumps in the United States. The New Journal England of Medicine 2008;358:1580-1589

3. Hardy, JB. Viral infection in pregnancy: a review. Am. J. Obstet. Gynecol. 1965;(93)7:1052-1065.

4. Dirección de vigilancia de la Salud. Boletín epidemiológico del Ministerio de Salud y Bienestar Social. Internet. Paraguay; 2018. Citado el 16 de abril de 2018. que no contaban con una vacunación completa. Pero no se registró ningún caso de defunción. El brote de parotiditis estudiado en este trabajo, fue diagnosticado a través de la clínica, en ningún caso fue tomado muestra para material de PCR, ni serología ya que no contábamos con disponibilidad en ese momento.

Las medidas de control de brote que fueron tomadas consistieron en la formación de cohortes y aislamientos de los mismos en el Liceo Militar, contando con asistencia de personal de blanco del servicio.

\section{CONCLUSIÓN}

El brote de parotiditis ocurrido en el Liceo Militar de

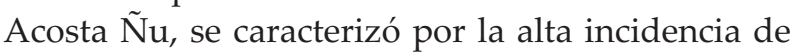
contagios. Al ser una Unidad Militar, la convivencia estrecha de un internado los hizo más susceptibles a contraer la enfermedad.

También la baja o nula cobertura vacunal, razón por la cual recomendamos que para ingresar a toda institución de internados una de las a exigencias mínimas debería de ser la presentación de un carnet de vacunación en forma completa.

\section{AGRADECIMIENTOS}

Cnel. San. Gladys Alegre de Arguello
Recuperado a partir de: http://www.vigisalud.gov.py/

5. Ministerio de Salud Pública y Bienestar Social, Dirección General de Vigilancia de la Salud, Programa Nacional de Enfermedades Inmunoprevenibles y PAI. Normas Nacionales de Vacunación, Técnico Administrativas y de Vigilancia del Programa Nacional de Enfermedades Inmunoprevenibles y PAI parte 1. Paraguay; 2016. Internet. Citado el 12 de abril de 2018. Recuperado a partir de: http://pai.mspbs.gov.py/article/manuales

6. Davidkin I, Jokinen S, Paananen A, et al. Etiology of Mumps-Like Illnesses in Children and Adolescents Vaccinated for Measles, Mumps, and Rubella. The Journal 
of Infectiuos deseases 2005;191(5):719:723.

7. Armsby C, Baron E, Barss V, et al. Patient education: Parotitis (The Basics). Internet. UpToDay; 2018. Citado el 18 de abril de 2018. Recuperado a partir de: https://www.uptoday.com

8. López P, Riedemann S. Virus de la Parotiditis y Seguridad de las Cepas Utilizadas para su Prevención: Diversos Cuadros Clínicos Producidos por el Virus de la Parotiditis y Seguridad de las Cepas Utilizadas para su Prevención 2015. Revista Colombiana de Pediatría. Internet. Citado el 16 de mayo de 2016. 2015; 37(2). Recuperado a partir de: https://encolombia.com/medicina /revistas-medicas/pediatria/vp-372/pediatria37202diversos/

9. American Academy of Pediatrics (Papera). En: Pickening LB, Baker CJ, Kimberlin DW, Long SS. Editores. Red Book: Informe 2015 del comité sobre Enfermedades Infecciosas. $30^{\circ} \mathrm{ed}$. American Academy of Pediatrics; 2015 p. 514-515- 516.

10. Compés C, Guimbao J, Gaspar J, Lázaro MA, Azmar A. Brote Escolar de Parotiditis: Estimación de la Efectividad Vacunal. Enfermedades Infecciosas y Microviología Clínica. 2015;33 (6):385-390. 